\title{
El IAPH presenta el nuevo canal web de patrimonio contemporáneo
}

Tras dos años de trabajo, el Instituto Andaluz del Patrimonio Histórico presenta el nuevo canal web de patrimonio contemporáneo, con el objetivo de ofrecer un marco de referencia a la investigación, la difusión y la intervención en dicho singular patrimonio. Concebido como un instrumento de información, se persigue disponer de una herramienta digital que integre aquellas noticias de interés, referencias a eventos realizados, reseñas de publicaciones, etcétera con la intención de dar a conocer las iniciativas que conciernan al patrimonio arquitectónico contemporáneo andaluz.

El Centro de Documentación y Estudios del Instituto Andaluz del Patrimonio Histórico (IAPH) trabaja desde 2007 en la elaboración de una herramienta web que recoja todas aquellas iniciativas realizadas sobre patrimonio contemporáneo en el marco geográfico de Andalucia. Concebido como un instrumento de información, da muestra del interés del IAPH por apoyar y potenciar el estudio, la difusión y la intervención sobre este legado histórico casi desconocido en su tarea de documentar y promover su protección organizando, gestionando y difundiendo actividades de fomento de dicho patrimonio.

Poder ofrecer información actualizada de la actividad realizada y prevista del
Desde el Centro de

Documentación y Estudios

se propone una herramienta

web que recoja todas aquellas

iniciativas sobre patrimonio

contemporáneo en el marco

geográfico de Andalucía

IAPH y otras entidades en materia de patrimonio contemporáneo; hacer accesible dicha información al mayor número de personas con la rapidez que precisa la continua convocatoria de actividades programadas nacional e internacionalmente; y la necesidad de estar presente

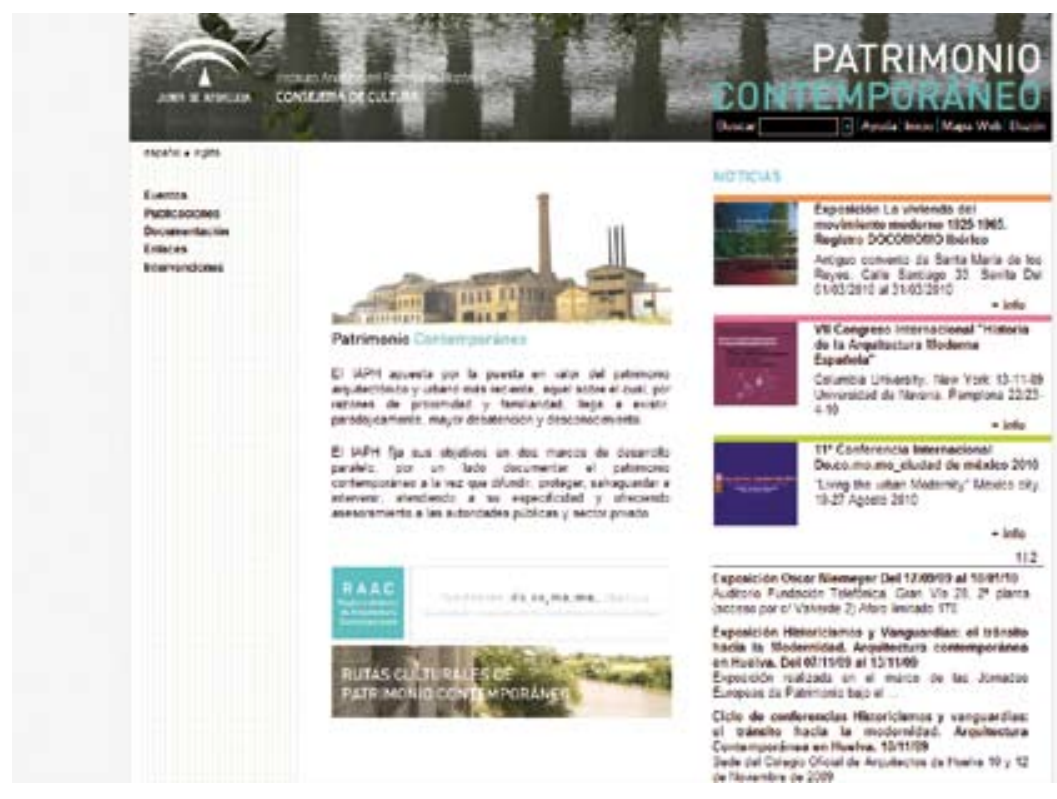

Página de inicio del canal de patrimonio contemporáneo: www.juntadeandalucia.es/cultura/iaph/ patrimoniocontemporaneo y en contacto con las numerosas instituciones con las que el IAPH habitualmente colabora, fueron las razones que motivaron la demanda de difusión mediante una sección temática propia.

La información se presenta ordenada según tres criterios. Por un lado, se ofrece clasificada en cinco apartados: eventos, publicaciones, documentos, enlaces e intervenciones. Los dos primeros recogen las actividades de fomento del patrimonio arquitectónico contemporáneo propuestas tanto por el IAPH como por otras instituciones tales como exposiciones, conferencias, congresos, seminarios, cursos, publicaciones, concursos de ideas y otros eventos relacionados. El tercer y cuarto apartado recogen un selección de elementos considerados de relevancia para la investigación y estudio de este patrimonio tales como estudios e inventarios, documentos, referencias bibliográficas y enlaces de interés. Por último, un quinto apartado recoge una selección de actuaciones de conservación realizadas sobre bienes del patrimonio contemporáneo a nivel internacional que pretende establecer un marco teórico para la intervención.

A su vez, los contenidos se organizan cronológicamente de manera que se consigue presentar una agenda de programación en los dos primeros apartados. Por último, con objeto de trasladar la lógica de funcionamiento reticular del programa de patrimonio contemporáneo desarrollado desde el Centro de Documentación y Estudios del IAPH, los contenidos se relacionan transversalmente en cada una de las fichas.

Con la creación de este nuevo canal se busca atender a la creciente demanda del colectivo de profesionales implicados en el estudio, la difusión y la intervención en el patrimonio contemporáneo dotando de un sitio en el que obtener información y ampliar el conocimiento en esta materia. 